\title{
Central Neurogenic Hyperventilation Secondary to a Critic Thyroid Status after Aortoaortic Bypass
}

\author{
Ana Belén Fernández M.D. \\ Staff of Department of Anesthesiology and Critical Care Unit \\ Department of Anesthesiology and Critical Care Unit. Ntra Sra de Candelaria University Hospital \\ Santa Cruz de Tenerife (Canary Island) (Spain) \\ anabfp@gmail.com
}

Keywords: lactic acidosis, metabolic acidosis, myxedema coma, central neurogenic hyperventilation

Running Head: Central Neurogenic Hyperventilation and Critic Thyroid Status

Central neurogenic hyperventilation $(\mathrm{CNH})$ was defined for the first time by Plum and Swanson in 1959 as a syndrome with decrease in $\mathrm{PaCO} 2$, increase in $\mathrm{PaO} 2$ and respiratory alkalosis with no other clinical or radiological feature of pulmonary disorder.

The main causes of hyperventilation are: pulmonary embolism, severe asthma attack, pneumothorax, myocardial ischemia, congestive heart failure, hyperthyroidism, pheochromocytoma, alcohol and drugs, severe metabolic acidosis, fever, acute pain, ischemia and traumatism. Even if most of $\mathrm{CNH}$ are caused by CNS tumours, especially lymphomas, invasion of brain tissue may produce tissue acidosis and develop hyperventilation.

In our literature research we found 6 cases of postsurgical $\mathrm{CNH}$ : 3 of them were after endoscopic ventriculostomy, 1 after anaplastic astrocytoma resection and 2 after general anesthesia in non neurosurgical procedures.

We report a case of a 63-year-old man scheduled for elective aortoaortic bypass graft surgery due to a $70 \mathrm{~mm}$ aortic aneurysm. The patient suffered from hypertension and dyslipidemia and he was in treatement with ARBs and statins. There had been no reports of previous cerebrovascular diseases.

During the procedure, a hemorrhagic shock took place and the patient was transfused with: 8 red blood cell units, $1500 \mathrm{cc}$ plasma and 4 grams of fibrinogen. He arrived in the intensive care unit hemodynamically stable and breathing on a venturi mask. The arterial gasometry values at the moment were: pH 7.20, pO2 90, pCO2 45, $\mathrm{HCO} 3$ 15, BE -7, lactate 8.5, $\mathrm{SpO} 296 \%$.

Acidosis was resolved within the next 24 hours. During the early postoperative phase, an acute renal failure took place with creatinine values of 2,8 and uremia of 120 . He also suffered a paralytic ileus that was easily solved with IV prokinetics. Lactate levels stayed increased between 2,5-3, and hemoglobine was $10 \mathrm{gr} / \mathrm{dl}$.

Four days after surgery, the patient started to feel sleepy, hypothermic and developed an important cognitive impairment. His breathing rate was $50 \mathrm{bpm}$ and he didn't answer to easy orders. The arterial gasometry values with $4 \mathrm{lpm}$ nasal cannula support were:

pH 7.60, pO2 80 mm Hg; pCO2 16 mm Hg; HCO3 18 mmol/L; BE -10 mmol/L; Lactate 4, SpO2 $95 \%$.

A cranial CT-scan and MRI were performed along with an echocardiogram, chest X-ray, D-dimer and biochemical analysis. The results were normal with the exception of: creatinine 1.5, urea 47, TSH $0.001 \mathrm{microUI} / \mathrm{mL}$ (normal values $0,270-4,200$ ) and T4 0,1 ng/dl (normal values $0,93-1,70$ ). 
$400 \mathrm{mg}$ IV Hydrocortisone was administered every 24 hours in order to avoid an acute adrenal crisis. In addition, a bolus of 300 microgr IV levothyroxine was given, followed by daily doses of 100 microgr to treat hypothyroidism.

A normal cognitive level, breathing pattern and lactate values were achieved within the next 24 hours.

Hyperlactatemia physiopathology as a cause of $\mathrm{CNH}$ is not well known. It is suspected that bicarbonate produced as a result of high lactic acid levels could cross blood brain barrier, resulting in metabolic alkalosis and increasing $\mathrm{CO} 2$ levels. As a result, the chemoreceptors responsible for the development of hyperventilation are activated.

The start of a critically ill patient hypothyroidism in just 4 days is not common. Our patient did not need support of mechanical ventilation, benzodiazepines administration or other drug that could affect the thyroid axis. As analgesic drug we used IV fentanyl, this may have decreased the severity of CNH as the publications of Adachi YU et al have suggested (8), it could be a good palliative treatment in $\mathrm{CNH}$ secondary to advanced tumours.

As a conclusion, we report Hypothyroidism Coma in critically ill patient showing up as $\mathrm{CNH}$, as an important postoperative complication in abdominal aortic aneurysm surgery,

This could possibly be the first $\mathrm{CNH}$ case reported in this context at the time.

It is important to consider this option in our differential diagnosis when we confront a postsurgical patient after major surgery with polytransfusion and organ failure.

\section{REFERENCES}

[1] Plum F, Swanson AG. Central Neurogenic hyperventilation in man. Arch Neurol Psychiatry 1959; 81:535-49.

[2] Fabregas N, López A, Valero R, Carrero E, Caral I, Ferrer E: Anesthetic management of surgical neuroendoscopies: usefulness of monitoring the pressure inside the neuroendoscope. J Neurosug Anesthesiol 12: 21-28, 2000.

[3] Kim G, Bae JH, Lim SW: Hyperventilation attack during recovery from general anesthesia: a case report. Korean J Anesthesiol 49: 735-738, 2005.

[4] Mizuno J, Morita S, Itou Y, Honda M, Momoeda K, Hanaoka K: Hyperventilation syndrome before induction of and after awakening from general anesthesia. Masui 58: 768-771, 2009.

[5] Sung HJ, Sohn JT, Kim JG, Shin IW, Ok SH, Lee HK, et al: Acute respiratory alkalosis occurring after endoscopic third ventriculostomy: a case report. Korean J Anesthesiol 59: S194-S196, 2010.

[6] Hae Mi Lee, Kyung Bae Shin, Seong Ho Kim, Dae Lim Jee. An acute postoperative intractable hyperventilation after an endoscopic third ventriculostomy. J Korean Neurosurg Soc 51: 173-176, 2012.

[7] Flavio A. Carvalho, Ricardo O.H. Maciel, Eduardo L.V. Costa, Tenille Bernardino, Sèrgio F.A. Felizola, Gisele S. Silva. Central Neurogenic Respiratory Failure: A challenging diagnosis. Case Rep Neurol 3: 75-81, 2011.

[8] Adachi YU, Sano H, Doi M, Sato S. Central hyperventilation treated with intravenous fentanyl followed by transdermal application. J Anesth 21(3): 417-9, 2007. 